\title{
AN ERROR IN ICE-TEMPERATURE MEASUREMENT
}

\author{
By T. J. O. SANDERSON \\ (British Antarctic Survey, Madingley Road, Cambridge $\mathrm{CB}_{3}$ oET, England)
}

\begin{abstract}
An analysis is made of the disturbance in conductive heat flow caused by drilling a bore hole in ice in which there is a vertical temperature gradient. The model used is that of a perfectly insulating hole placed in a linear temperature gradient; it is shown that the temperature measured at the bottom of the hole deviates from its value before drilling by an amount of order $-0.6 a U$ where $a$ is the bore-hole radius and $U$ is the temperature gradient. The deviation takes effect in a few hours. The error is typically between 0.005 and $0.1 \mathrm{deg}$ and is therefore significant only where very high accuracy is required. It should not be present in temperate glaciers, nor where the thermometer is properly frozen in, nor if temperatures are measured at the bore-hole walls far above the bottom.

RÉsumÉ. Une erreur dans la mesure de la température de la glace. On analyse le trouble apporté dans la propagation dans le flux de chaleur de conduction par le forage d'un puits dans la glace dans lequel il y a un gradient vertical de température. Le modèle utilisé est celui d'un puits parfaitement isolé placé dans un gradient linéaire de température. On montre que la température mesurée au fond du trou dévie de sa valeur d'avant le forage d'un ordre de grandeur de $-0,6 a U, a$ étant le rayon du puits et $U$ le gradient de température. La déviation se produit en quelques heures. La déviation est généralement entre o,o5 et 0,1 deg et n'est donc significative que si on demande une grande précision. Elle ne devrait pas de produire dans les glaciers tempérés ni lorsque le thermomètre est regelé dans la masse, ni si les températures sont mesurées sur les murs du puits loin au-dessus du fond.

Zusammenfassung. Ein Fehler bei der Messung von Eistemperaturen. Es wird die Störung des konduktiven Wärmeflusses analysiert, die beim Bohren eines Loches in Eis entsteht, in dem ein vertikaler Temperaturgradient herrscht. Das benutzte Modell ist das eines vollständig isolierenden Loches in einem linearen Temperaturgradient; es wird gezeigt, dass die am Boden des Loches gemessene Temperatur von dem Wert vor der Bohrung um einen Wert der Grösse -o,6aU abweicht, wobei $a$ den Bohrlochradius und $U$ den Temperaturgradienten bedeuten. Die Abweichung tritt nach wenigen Stunden ein. Der Fehler liegt gewöhnlich 0,005 und $0,1 \mathrm{deg}$ und muss deshalb nur bei Messungen hoher Genauigkeit berücksichtigt werden. Er sollte in temperierten Gletschern nicht auftreten, aber auch dann nicht, wenn das Thermometer richtig eingefroren ist und wenn Temperaturen an den Bohrlochwänden weit über dem Boden gemessen werden.
\end{abstract}

Temperature measurements at the bottom of bore holes in polar glaciers have generally been subject to a small error due to the presence of the bore hole. Such an error arises through disturbance of the heat flow pattern in the ice, for where before drilling there was a solid mass of ice there is afterwards a column of relatively poorly conducting air. This leads to constriction of heat flow lines and an anomalous temperature at the very bottom of the hole. The error is positive or negative depending on the sign of the temperature gradient, but it is not present at all in temperate glaciers, where the gradient is effectively zero. It is also not present for measurements taken away from the bottom of the hole.

Precautions have been taken in the past against convective air currents and radiation, and the effect of the drilling process has been analysed (Bullard, 1947), but no attention has been paid to the disturbance caused by the hole itself. Three methods typically in use involve: (i) lowering a thermometer to the bottom of the hole (Schytt, 1960); (ii) wrapping a probe in foil and then packing loose snow around it (Schytt, 1960); or (iii) lowering a probe and then a polystyrene disc immediately above it (Thomas, 1976). The last two methods help prevent problems with air convection and with radiation, and the second goes some way towards refilling the hole. Consider, however, the thermal conductivities for air and for various densities of ice, firn and snow, as given in Table I (data from Van Dusen, 1929). The conductivities of firn and ice are one or two orders of magnitude greater than the conductivity of air, and it is therefore valid as a first approximation to model an unfilled bore hole as a perfectly insulating bung in a conducting solid. It is further seen that even packing the hole with loose snow is not a great improvement, for such a filling will have a conductivity still about an order of magnitude down on that of the surrounding firn. We shall therefore use the model of an insulating bung and assume also that the effects of radiation and convection are either negligible or prevented.

Let us look at the effect of such a bung placed in a linear temperature gradient $U$. We need to find a scalar temperature field $T(r, z)$, coordinates defined as in Figure I, which satisfies Laplace's equation for the null divergence of heat flow,

$$
\nabla^{2} T=0 .
$$


The important boundary condition is that at the ice-bore-hole interface we have zero heat conduction. This means that

$$
\frac{\partial T}{\partial z}=0 \text { along } \mathrm{BC} \text { and } \frac{\partial T}{\partial r}=0 \text { along } \mathrm{AB} \text { and } \mathrm{CD},
$$

and the complete solution involves applying the further condition that:

$$
\frac{\partial T}{\partial z} \rightarrow U \text { as } r \rightarrow \infty \quad \text { and } \quad \text { as } z \rightarrow \infty .
$$

A two-dimensional version of this problem may be solved for the region around the bottom of the hole by use of hydrodynamical theory (Milne-Thomson, I967, p. 266-67): we take the complex potential field for uniform flow along a straight-line boundary, and then use a conformal mapping, the SchwarzChristoffel transformation, to put a simple step into the boundary. The problem is then that of flow over a step in the bed of a deep stream. The conformal mapping preserves both Laplace's equation and the local boundary conditions and so still represents a proper solution, with the temperature gradient approaching $U$ far away from the step. We can then apply the principle of reflection to give the potential field for flow around a submerged rectangular obstacle.

This provides the temperature distribution for flow of heat around an infinite insulating slot of half-width $a$, and the results show that temperature deviations are proportional to $-a U$ where $U$ is the temperature gradient, considered as positive when the temperature decreases with depth. In particular, if $T_{0}$ is the temperature before cutting the slot, the temperature at the centre of the bottom of the slot at equilibrium afterwards is $T_{0}-1.48 a U$ and at the edge is $T_{0}-0.8_{3} a U$.

TABle I. Thermal Conductivity of ICE, FIRn, SNOW AND AIR

$\begin{array}{lcc}\text { Density } & \begin{array}{c}\text { Thermal } \\ \text { conductivity } \\ \mathrm{W} \mathrm{m} \mathrm{m}^{-1} \mathrm{~K}^{-1}\end{array} \\ \text { Ice } & 0.92 & 2.09 \\ & 0.80 & 1.46 \\ \text { Firn } & 0.6 \mathrm{o} & 0.74 \\ & 0.40 & 0.33 \\ \text { Loose snow } & 0.20 & 0.12 \\ \text { Air } & 0.10 & 0.065 \\ & - & 0.022\end{array}$

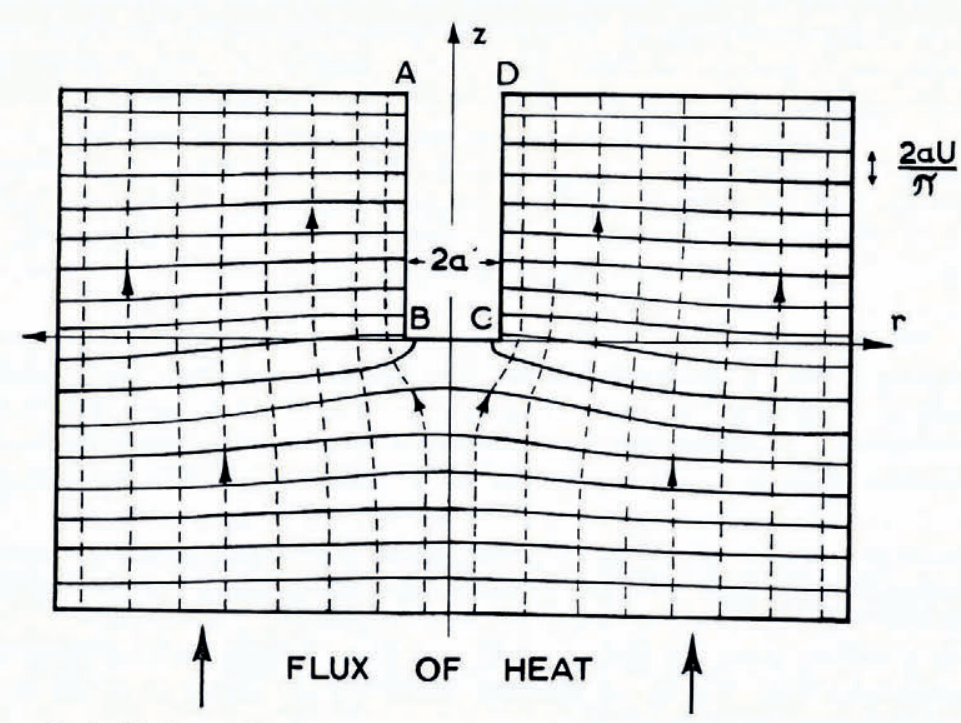

Fig. $x$. Section through slot-like bore hole in ice, showing disturbance of flow lines (dashed lines) and isotherms (solid lines). The diagram is drawn for negative $U$ and isotherms are drawn at intervals of $2 a U / \pi$. 
Of more interest is the three-dimensional case with cylindrical symmetry about the $z$ axis, which forms a much better model of a real bore hole. Unfortunately the foregoing theory cannot be directly carried over to three dimensions since the conformal mapping used applies essentially to a space which can be represented on an Argand diagram. However, it is to be expected that the magnitude of the effect will be modified at most by a factor of order unity, as can be seen by reference to a similar problem in standard heat-flow theory (Carslaw and Jaeger, 1959, p. 426). This involves looking at heat flow horizontally around a vertical cylinder, and then around a sphere of the same radius. The temperature deviation on the up-stream surface is found (using our notation) to be

$$
-(2 a U-a U)=-a U
$$

in the first case, and

$$
-\left(\frac{3}{2} a U-a U\right)=-\frac{1}{2} a U
$$

in the second. It therefore seems fair to modify our results by a factor of $\frac{1}{2}$ in carrying them over from two to three dimensions. This gives a deviation of order $-0.7 a U$ at the centre of the bottom of the hole, and of order $-0.4 a U$ at the edge. It is interesting to note that these magnitudes are consistent with results from an alternative, though not quite so appropriate, mathematical model: that of heat flow around an oblate spheroid. For this problem analytical solutions exist (Carslaw and Jaeger, 1959, p. 427) and for the limiting case of a flat spheroid of radius $a$ in temperature gradient $U$, the deviation at the centre is found to be $-2 a U / \pi$ or $-0.64 a U$. This deviation is, as expected, slightly less than that due to the semi-infinite cylinder.

The error is small but not always insignificant. Temperature gradients encountered in the top ten metres of polar ice are generally in the range 0.1 to $2.0 \mathrm{deg} \mathrm{m}^{-1}$. For a $12 \mathrm{~cm}$ diameter bore hole, as drilled for instance by the SIPRE 3 inch $(7.6 \mathrm{~cm})$ coring auger, these gradients lead to temperatures at the bottom of the hole as tabulated in Table II, taking $-15^{\circ} \mathrm{C}$ to be the temperature before drilling. The temperatures are tabulated as a function of distance from the bore-hole axis. For a thermometer not actually in contact with the ice, but measuring the air temperature at the very bottom, the reading may be expected to correspond to the average ice temperature over the base. The appropriate areal integral is shown in the last line of the table, and has a value of order $-0.6 a U$.

Table II. Temperatures at bottom OF $12 \mathrm{~cm}$ Diameter BORE HOLE: TEMPERATURE OF $-15^{\circ} \mathrm{C}$ BEFORE DRILLING

\begin{tabular}{|c|c|}
\hline \multicolumn{2}{|c|}{ Temperature } \\
\hline $\begin{array}{l}\text { (i) for gradient } \\
0.1 \text { deg m-1 } \\
{ }^{\circ} \mathrm{C}\end{array}$ & $\begin{array}{l}\text { (ii) for gradient } \\
2.0 \mathrm{deg} \mathrm{m} \mathrm{m}^{-1} \\
{ }^{\circ} \mathrm{C}\end{array}$ \\
\hline-15.004 & -15.09 \\
\hline-15.004 & -15.09 \\
\hline-15.004 & -15.09 \\
\hline-15.004 & -15.08 \\
\hline-15.004 & -15.08 \\
\hline-15.003 & -15.07 \\
\hline-15.003 & -15.05 \\
\hline-15.004 & -15.07 \\
\hline
\end{tabular}

Distance from
bore-hole axis
$\mathrm{cm}$
0
$\mathrm{I}$
2
3
4
5
6
areal integral

Because the sign of the error is dependent on the sign of the temperature gradient it can become doubly important when measuring variation of bore-hole temperature in the course of a year, for the gradient in the top ten metres generally reverses with the seasons. At five metres, for instance, in Antarctica, Schytt (196o, p. 16o-6r) found a gradient of $+1.2 \mathrm{deg} \mathrm{m}^{-1}$ in April and of $-\mathrm{r} .0 \mathrm{deg} \mathrm{m}^{-1}$ in August. Temperatures were measured by fairly efficient burial of probes in narrow bore holes, but if measured in unfilled, wider holes readings at this depth could have been in error by $0.05 \mathrm{deg}$, and their difference in error by o.I deg. The same error would be present in comparing the temperatures for two depths at which the temperature gradient was of opposite sign. At ten metres depth seasonal variations are well smoothed and gradients are generally less than $\pm 0.1 \mathrm{deg} \mathrm{m}^{-1}$, so that the error is less than $0.005 \mathrm{deg}$; this is small enough to have no effect on the use of $10 \mathrm{~m}$ temperatures as mean annual temperatures for dry snow facies, as such use is theoretically valid only to $1 \%$ of the surface variation, or about $0.3 \mathrm{deg}$ (Sorge, 1935; Benson, 1962, p. 44-6o; Loewe, 1970). 
An estimate may be made of the time taken for the ice to attain its new state by considering the heat flow into a region at the bottom of the hole. An exact solution is difficult, but consider a cylinder of radius and depth $a$ immediately below the bore hole: this is a representative order of volume for the effect, and immediately after drilling it has a gradient of $U$ at its lower boundary and of zero at its upper boundary, where there is zero heat flow. There is therefore an initial rate of heat flow of:

$$
k\left(0-\frac{\partial T}{\partial z}\right) \pi a^{2}=-k U \pi a^{2}
$$

into a volume of $\pi a^{3}$, where $k$ is the thermal conductivity of ice. So, the initial rate of change of temperature is:

$$
\frac{\mathrm{d} T}{\mathrm{~d} t}=\frac{-k U \pi a^{2}}{c \rho \pi a^{3}}
$$

averaged over this volume, where $c$ is the specific heat capacity of ice, and $\rho$ the density.

But we can take

$$
\delta T \approx-\frac{a U}{2}
$$

so

$$
\delta t \approx \frac{c \rho a^{2}}{2 k} .
$$

Now $a \approx 0.06 \mathrm{~m}$, and for ice $c=2.01 \times 10^{3} \mathrm{~J} \mathrm{~kg}^{-1} \mathrm{~K}^{-1}, \rho=0.92 \mathrm{Mg} \mathrm{m}^{-3}$ and so

$$
\delta T \approx \mathrm{r} 600 \mathrm{~s} \text {, or about } \frac{1}{2} \text { hour. }
$$

For firn of density $0.40 \mathrm{Mg} \mathrm{m}^{-3}$ a similar calculation gives

$$
\delta T \approx \mathrm{I} \frac{1}{4} \text { hours. }
$$

These give the order of time taken for the effect to become appreciable, though it is not obvious what form the cooling (or warming) curve should follow. Studies have been made of the cooling laws to be expected for the re-equilibrium of bore holes after thermal drilling, and they have given nonexponential laws. Philberth ( 1962$)$ treats the case of a thermal drill supplying heat at rate $\dot{q}$ descending at a constant velocity $v$ through ice of thermal conductivity $k$ and calculates that the temperature deviation $\Delta T$ follows a hyperbolic law:

$$
\Delta T<\frac{\mathrm{I}}{4^{\pi \sqrt{ } 2}} \cdot \frac{\dot{q}}{v k t}+\epsilon
$$

where $\epsilon$ is a small exponential decay term. Bullard (1947) considers a slot-like bore hole warmed by temperature $\Delta T_{\mathrm{o}}$ for time $t_{\mathrm{o}}$ and finds that after time $t$ the temperature deviation is:

$$
\Delta T=\Delta T_{0}\left[1-\frac{2}{\pi} \tan ^{-1} /\left(\frac{t}{t_{0}}\right)\right] .
$$

These models are not appropriate to the case in question, but almost whatever time dependence actually occurs we can still say that the process has a time scale of about an hour. It might seem from this that if measurements can be made more quickly, then the effect is avoided; however, the problem is not simple because measurements made directly after drilling suffer from the effects of frictional and thermal heat from the drill, the effect of warmer snow knocked down from higher levels and the influx of air from the surface-effects which may take the same order of time or longer to dissipate.

The error may be eliminated by thorough burial for a long period (Miller, 195I) or by freezing-in, which makes retrieval difficult (Harrison, 1975), and also by measurement of wall temperature far above the bottom (Mellor, 1960). For rapid field measurements apparatus is being designed to insert a slim platinum resistance probe to a depth of $20 \mathrm{~cm}$ below the bottom of the bore hole. This should give a reading before changes due to the drill and the hole take effect, and should also avoid effects due to air convection and radiation. 


\section{Acknowledgements}

I wish to thank colleagues at the British Antarctic Survey for useful discussions, and an anonymous referee for drawing my attention to the reference by Philberth and to the treatment using oblate spheroids.

MS. received 12 October 1976 and in revised form 18 January 1977

\section{REFERENCES}

Benson, C. S. 1962. Stratigraphic studies in the snow and firn of the Greenland ice sheet. U.S. Snow, Ice and Permafrost Research Establishment. Research Report 70.

Bullard, E. C. 1947. The time necessary for a borehole to attain temperature equilibrium. Monthly Notices of the Royal Astronomical Society. Geophysical Supplement, Vol. 5 No. 5, p. 1 27-30.

Carslaw, H. S., and Jaeger, J. C. 1959. Conduction of heat in solids. Second edition. Oxford, Clarendon Press.

Harrison, W. D. 1975. Temperature measurements in a temperate glacier. Journal of Glaciology, Vol. 14, No. 70, p. 23-30.

Loewe, F. 1970. Screen temperatures and io $m$ temperatures. Journal of Glaciology, Vol. 9, No. 56, p. $263-68$.

Mellor, M. 196o. Temperature gradients in the Antarctic ice sheet. Journal of Glaciology, Vol. 3, No. 28, p. 773-82.

Miller, M. M. r 95 I. Englacial investigations related to core drilling on the upper Taku Glacier, Alaska. Fournal of Glaciology, Vol. I, No. 10, p. 579-80.

Milne-Thomson, L. M. 1967 . Theoretical hydrodynamics. Fifth edition. London, Macmillan.

Philberth, K. 1962. Une méthode pour mesurer les températures à l'intérieur d'un inlandsis. Comptes Rendus Hebdomadaires des Séances de l'Académie des Sciences (Paris), Tom. 254, No. 22, p. $3881-83$.

Schytt, V. 1960. Glaciology. II. Snow and ice temperatures in Dronning Maud Land. Norwegian-BritishSwedish Antarctic Expedition, 1949-52. Scientific Results, Vol. 4, D.

Sorge, E. 1935. Glaziologische Untersuchungen in Eismitte. (In Brockamp, B., and others. Glaziologie, von B. Brockamp, H. Jülg, F. Loewe und E. Sorge. Leipzig, F. A. Brockhaus, p. 62-27o. (Wissenschaftliche Ergebnisse der deutschen Grönland-Expedition Alfred Wegener 1929 und 1930/1931, Bd. 3.))

Thomas, R. H. 1976 . The distribution of $10 \mathrm{~m}$ temperatures on the Ross Ice Shelf. Journal of Glaciology, Vol. 16 , No. 74 , p. I I $1-17$.

Van Dusen, M. S. 1929. Thermal conductivity of non-metallic solids. (In Washburn, E. W., ed. International critical tables of numerical data, physics, chemistry and technology. New York, McGraw-Hill Book Co., Vol. 5, p. 216-I7.) 